\title{
Review of Regulatory Programs and New Opioid Technologies in Chronic Pain Management: Balancing the Risk of Medication Abuse with Medical Need
}

\author{
David Fishbain, MD, FAPA; Sandra Johnson, JD, LLM; Lynn Webster, MD, FACPM, FASAM; \\ Laurence Greene, PhD; and Joanne Faysal, BS
}

$\mathrm{T}$ he complaint of pain is among the most common reasons that patients seek health care, and it is a leading cause of disability in our society. ${ }^{1}$ Approximately 130 million people in the United States report suffering from chronic pain, often in multiple anatomic locations simultaneously. ${ }^{2-7}$ Patientreported pain is associated with estimated economic costs that range between $\$ 100-\$ 150$ billion annually in the United States. ${ }^{2-7}$ As generally recognized by pain medicine specialists, an essential component to managing legitimate chronic pain is opioid therapy. However, over the last 2 decades, greater numbers of opioid medication prescriptions have been accompanied by disturbing increases in accounts of opioid misuse, abuse, and diversion. ${ }^{8}$ As recently described by Strassels (2009) in this journal, the societal and economic costs of opioid abuse are considerable. ${ }^{9}$ Compared with nonabusers, opioid abusers use significantly more medical services, experience far greater numbers of opioid- and nonopioid-related adverse events, and are at high risk for abuse-related diseases. ${ }^{10}$

Regarding opioid therapy, a cornerstone of effective pain management involves the challenges of providing appropriate analgesia for patients with legitimate pain while, at the same time, reducing risks of aberrant drug-related behaviors and preventing their negative outcomes. Current efforts to meet these challenges include applying effective strategies for diagnosing the underlying causes of pain; using valid screening tools to identify patients who are at risk for abuse; regularly monitoring patients for potential misuse and abuse; following government-based regulatory policies and guidelines of established pharmacy and medical organizations for prescribing and dispensing opioids; and participating in prescription drug monitoring programs (PDMPs). In addition, manufacturers have recently begun marketing novel opioid formulations with technologies intended to deter abusers who tamper with products to extract active substances for administration through alternative methods, including intravenous injection and nasal snorting. The primary purpose of this article is to provide the managed care pharmacy community with an overview of these various strategies for achieving balance involving opioid need versus the risk of abuse. For essential background information, we begin with brief summaries of key definitions of pain, current views on path pathophysiology, and pain pharmacotherapies.

\section{Defining Pain}

The International Association for the Study of Pain (IASP) defines pain as an "unpleasant sensory and emotional experience associated with actual or potential tissue damage."11 In addition, the IASP acknowledges that reported pain without tissue damage or any known pathophysiological cause is common in chronic pain patients. This problem is not necessarily associated with psychological dysfunction, psychiatric illness, factitious illness, or malingering and may be related to a physician's inability to diagnose pathophysiological dysfunction because of the current level of scientific development. ${ }^{11}$ An example of this phenomenon is fibromyalgia, a disease characterized by an apparent lack of pathophysiological cause. Because of this lack fibromyalgia was originally labeled "psychogenic rheumatism." However, up-to-date evidence utilizing recently developed technology (e.g., magnetic resonance imaging [MRI] and positron emission tomography [PET] scanning) indicates that fibromyalgia is probably a central sensitization syndrome characterized by abnormal pain processing. Nonetheless, in spite of the findings from newer technologies, it should be noted that there is usually a significant psychiatric comorbidity (e.g., depression, anxiety) found in patients with chronic pain. ${ }^{12,13}$ At the present time, the preponderance of the evidence indicates that the psychiatric comorbidity may be a result of the pain rather than its cause, since in most cases, psychiatric comorbidity follows pain development. ${ }^{12,13}$ However, generally the presence of psychiatric comorbidity, whatever its cause, complicates pain treatment. Proper prescribing comes from balancing these perspectives.

Specific definitions of pain are based on its persistence over time and underlying physical and psychological causes. Acute pain is a protective mechanism that typically develops from a specific physical cause and resolves in a short time following causal resolution. Chronic pain is commonly defined as persistent pain that lasts beyond the ordinary duration of time that an injury needs to heal. As defined in the Diagnostic and Statistical Manual of Mental Disorders, Fourth Edition, Text Revision (DSM-IV-TR), pain disorder refers to the complaint of chronic pain in which psychological factors play a major role in the onset, severity, exacerbation, or maintenance of pain. ${ }^{14}$ However, pain disorder is not synonymous with chronic pain. 


\section{Review of Regulatory Programs and New Opioid Technologies in Chronic Pain Management: Balancing the Risk of Medication Abuse with Medical Need}

The complaint of pain may also be a means to fulfill other agendas, such as obtaining opioids for illegitimate purposes.

Regarding causal factors, pain is commonly designated by the terms nociceptive, neuropathic, inflammatory, functional, somatoform, or existential. While acute pain mainly results from nociceptive stimuli, chronic pain can be produced via nociceptive, neuropathic, existential, or mixed stimuli. ${ }^{15}$ Inflammatory pain is the result of increased nociceptor excitability in response to inflammatory mediators. Existential pain, which is essentially anguish, often results in the overstatement of physical pain and commonly promotes addiction. Existential pain may be responsive to opiates; however, chronic use of opiates in patients with primarily existential pain promotes dysfunction and/or addiction. ${ }^{16-18}$

Pain disorder, a somatoform disorder, refers to the complaint of pain in which psychological factors play a large role in the development and severity of the pain. ${ }^{14}$ Pain disorder can be further differentiated into pain disorder with or without the presence of an underlying medical condition..$^{14}$ Patients with pain disorder typically present with persistent complaints of pain in one or more areas with a lack of physical cause and concomitant social impairment or distress due to their pain. Additionally, the complaint of pain in somatoform disorder is not associated with any dishonesty or malingering and cannot be correlated to any other mood, anxiety, or psychotic disorder. ${ }^{14}$

Differences in the causes of pain and length of its occurrence aid in determining the most appropriate management. Pharmacologic therapy may be utilized to help reduce, manage, and/or eliminate the pain, particularly when it is due to physical mechanisms, while antidepressants can help to alleviate any psychological causes or manifestations of pain. Furthermore, patients can experience more than one type of pain simultaneously, making treatment more complex.$^{19}$ A multidisciplinary approach to the management of pain-including physical, occupational, and psychosocial therapy-may thus be effective for reducing pain and treating common comorbidities such as depression. It is important to note that the experience of pain is subjective. There is no test or assay to positively diagnose pain; therefore, physicians must rely on the information provided to them by their patients. Opioid abusers can use this knowledge to their advantage to deceive physicians and obtain prescription opioids for personal use and/or diversion.

\section{Pathophysiology of Pain-A Brief Review}

A comprehensive review of the pathophysiology of pain goes well beyond the scope of this article. As follows, we present an overview of current views on the underlying mechanisms of pain as they relate to opioid therapy. Numerous publications address pain pathophysiology in considerable depth..$^{20-24}$

As previously stated, pain can involve dysfunction or injury to diverse neural pathways, as well as various psychiatric causes, wherein no specific pathway pathology may exist. ${ }^{19}$
Nociceptive pain, initiated by thermal, chemical, or mechanical stimuli, is attributable to signals transmitted along ascending pathways from peripheral pain receptors to the spinal cord and the thalamus. ${ }^{25}$ The thalamus functions as a relay station, sending signals to various areas of the cerebral cortex. Descending pathways can inhibit pain signaling through the release of neurotransmitters including norepinephrine and serotonin. Accordingly, antidepressant medications that modulate serotonin and norepinephrine levels are commonly prescribed to treat pain and related psychiatric disorders. ${ }^{26}$

Neuropathic pain, which is due to neural lesions or nervous system dysfunction, can be (a) induced by ectopic firing of nerves in axons or cell bodies; (b) a result of injured nerves releasing peptides, contributing to an inflammatory response; or (c) caused by inhibition of pathways in the brain and spinal cord involved in transmitting peripheral signals. ${ }^{25,27}$ Neuropathic pain is typified by numbness and tingling or burning sensations in the region innervated by the nerve and can be triggered by light touch. Prolonged neuropathic dysfunction can also result in spontaneous activity, emphatic conduction caused by aberrant signaling of adjacent neurons, sensitization, and neuroplasticity. ${ }^{23}$

While the viscera are generally impervious to chemical and noxious stimuli, there is a defined visceral sensitivity to mechanical stimuli, which is primarily mediated by inflammation. Inflammatory pain refers to spontaneous pain and hypersensitivity due to tissue damage or inflammation. ${ }^{20}$ Sensory afferent nerves are sensitive to inflammation and its chemical mediators, including bradykinins, prostaglandins, and leukotrienes. ${ }^{27}$ These mediators can directly activate nociceptors or recruit inflammatory cells to maintain or intensify inflammation. ${ }^{28}$ Stimulation of afferent neurons by inflammatory substances can cause peripheral sensitization, a change in neuronal function, or central sensitization, eventually leading to a chronic pain syndrome. Inflammation and its corresponding pain may also assist in the healing process by limiting mobility and increasing sensitivity to prevent further damage of the injured area.

Functional pain (non-nociceptive or non-neuropathic) may be due to abnormal pain processing or functioning of the nervous system, resulting in alloydonia and hyperalgesia. ${ }^{21}$ Fibromyalgia is a prototypical example of functional pain. Currently, the underlying cause of fibromyalgia is unknown, but diagnosis is based on the complaint of widespread pain lasting at least 3 months in 11 out of 18 tender point sites upon digital palpation. ${ }^{29}$

Sensitization occurs following repeated, constant, or intense stimuli of damaged tissue (peripheral sensitization) or neurons within the central nervous system (central sensitization). ${ }^{30}$ Both plasticity of the nociceptor and release of inflammatory mediators are involved in sensitization. ${ }^{25,30}$ When sensitization occurs, fewer stimuli are required to activate 


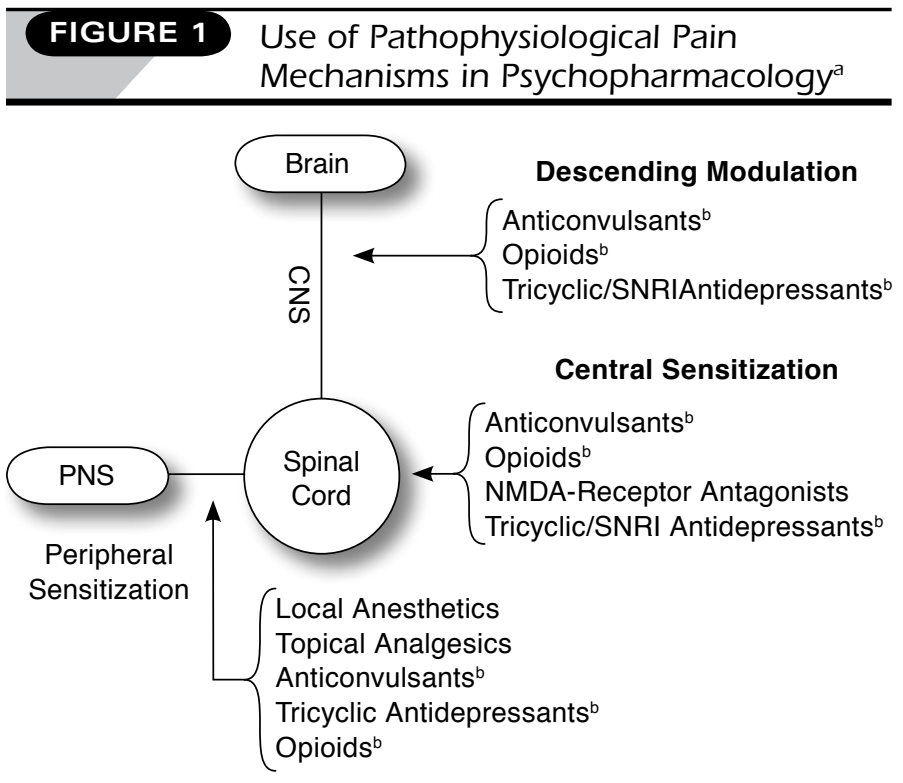

a Source: Fishbain 35

${ }^{b}$ Act at all 3 targets.

CNS = central nervous system; NMDA = N-methyl-D-aspartic acid; PNS = peripheral nervous system; SNRI= serotonin-norepinephrine reuptake inhibitor.

neurons, but a similar or exaggerated intensity of pain is produced. ${ }^{30}$ An important physiological event that contributes to the development of sensitization is wind-up. Wind-up is a continuous and/or an increased firing rate of neurons following repeated stimulation independent of whether a stimulus is present or not. ${ }^{31}$

Neuroplasticity refers to remodeling or adaptation of neurons following prolonged or repeated activation of neuroreceptors and the various neuronal pathways. ${ }^{32}$ Remodeling involves phenotypic and structural changes, increased excitability, and decreased firing threshold of neurons. The results of neuroplasticity are sensitization, restructuring, and overexpression of ion channels and receptors such as N-methyl-Daspartate receptors, activation of the hypothalamic-pituitaryadrenal axis, vasoconstriction, and neural reorganization. . $11,31,33^{2}$ Neuroplasticity can result in a decreased threshold for pain and opioid tolerance, thereby increasing the sensation of pain and reducing the effects of analgesia. ${ }^{34}$

\section{Pharmacotherapy of Pain}

It is important to differentiate the various types of pain during diagnosis, as each type is ideally managed with targeted therapies. Inflammatory pain is reduced upon healing of the injury, while the swelling and pain can be reduced using antiinflammatory medicines such as nonsteroidal anti-inflammatory drugs (NSAIDS) or corticosteroids. The treatment of nociceptive and neuropathic pain includes both opioids and a variety of psychoactive drugs. ${ }^{35}$ Treatments vary depending on the location of pain and the system involved; however, opioids can be used to treat pain emanating from anywhere within the nervous system (Figure 1). ${ }^{35}$ However, with the onset or progression of sensitization as described earlier, larger doses of opioids may be required to attain adequate analgesia, which can also contribute to the development of opioid dependence. While the prevalence rates for drug dependence are no greater in pain populations than in the general population, there are subgroups of chronic pain patients at an increased risk of dependence; typically, these are patients with an existing addiction predisposition. ${ }^{36}$ Thus, comprehensive monitoring is essential.

Antidepressants and anticonvulsants have been shown to assist in pain reduction by affecting neurotransmitters involved in modulating pain signals and by providing relief from psychological comorbidities. ${ }^{37}$ In addition, as there is a strong correlation between pain and psychiatric comorbidities, any reduction in pain through physical therapy, analgesics, or even narcotics can also help to reduce psychiatric symptoms. Three agents are approved by the U.S. Food and Drug Administration (FDA) for treating fibromyalgia: the secondgeneration anticonvulsant pregabalin and the dual-reuptake inhibitors duloxetine and milnacipran. For the management of fibromyalgia, guidelines from the American Pain Society (APS, 2004) cite strong evidence for efficacy for only 2 drugs, amitriptyline and cyclobenzaprine, and modest evidence of efficacy for tramadol, the selective serotonin reuptake inhibitor fluoxetine, pregabalin, venlafaxine (a dual-reuptake inhibitor), milnacipran, and duloxetine. ${ }^{38}$ In addition, the APS guidelines found no evidence of efficacy for corticosteroids, NSAIDs, or opioids and therefore do not recommend their use in patients with fibromyalgia syndrome..$^{38}$

According to the Merck manual, treatment for somatoform pain disorders revolves around treatment of both the psychiatric symptoms (e.g., antidepressants or psychotherapy) as well as the pain symptoms (e.g., analgesics). ${ }^{39}$ In addition, opioids can be a safe and effective treatment option for reducing pain in patients with somatoform disorder. ${ }^{39}$ However, there is a risk of the patient developing abuse or drug dependence, especially in patients with a history of drug abuse, and comprehensive monitoring should be utilized to prevent or reduce the risk of the development of dependence. ${ }^{36}$

\section{Opioid Use and Abuse}

Although Americans represent only $4.6 \%$ of the world population, they consume $80 \%$ of all opioids and $99 \%$ of all hydrocodone worldwide. ${ }^{40}$ Hydrocodone is the most frequently prescribed drug in the United States, with 120 million prescriptions written between 2005 and 2006..$^{40}$ According to the Drug Enforcement Administration (DEA) Automation of Reports and Consolidated Order Systems (ARCOS), cumulative distribution 


\section{Review of Regulatory Programs and New Opioid Technologies in Chronic Pain Management: Balancing the Risk of Medication Abuse with Medical Need}

\section{FIGURE 2 Cumulative Distribution of Opioids, 2003-2007ª}

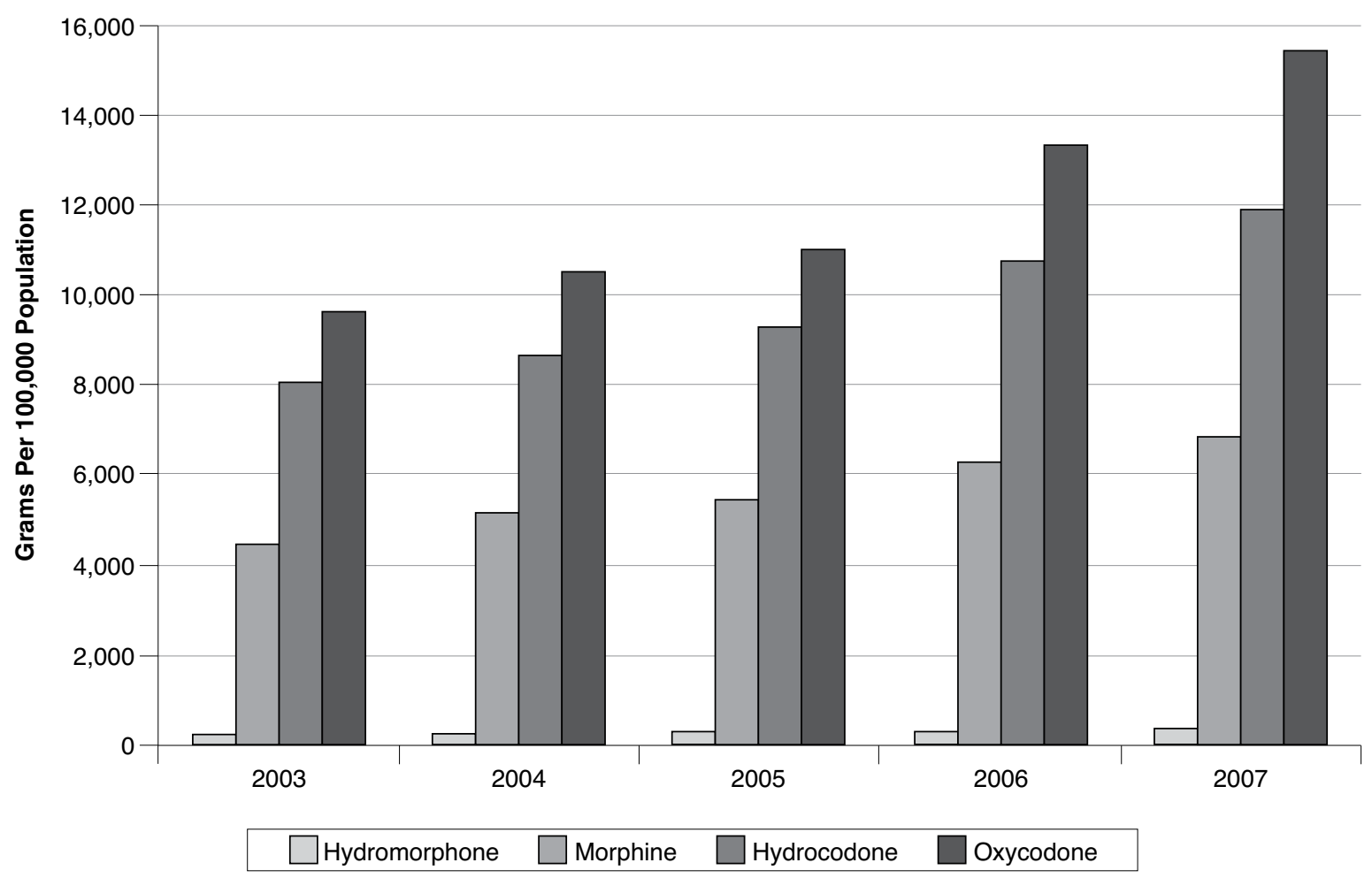

a Source: Drug Enforcement Administration ${ }^{41}$

of opioids has steadily increased from 2003 through 2007, with hydrocodone and oxycodone showing the largest distributions (Figure 2). ${ }^{41}$

When used appropriately, opioids provide effective analgesia for pain. However, there is a significant degree of illicit use of opioids that may include abuse, diversion, and addiction. These aberrant behaviors can result in death and societal harms. Specific definitions related to the use and abuse of opioids have been established by the Federation of State Medical Boards (Table 1). ${ }^{42}$

The fear of addiction may affect decisions made by both physicians and patients in determining the optimum treatment for chronic pain. While it is true that patients on long-term opioid treatment could possibly become addicted, Fishbain et al. (2008) determined in a review of 67 studies that the rates of abuse and addiction in chronic pain patients with or without previous or current history of drug abuse were $3.27 \%$ and $0.19 \%$, respectively. ${ }^{36}$ These findings suggest that patients with a history of drug abuse may require more stringent monitoring or referral to a pain specialist and/or psychiatric services.

Opioids are among the most frequently abused class of drugs. The 2008 National Survey on Drug Use and Health (NSDUH) revealed that approximately 4.7 million Americans took pain medications for nonmedical use within the last month. ${ }^{43}$ The NSDUH also found that pain relievers were among the most common drug classes for initial drug abuse, the second-ranked drug class associated with abuse or dependence, and the fourth-ranked drug class for which abuse-related treatment was sought among persons aged 12 years or older. ${ }^{43}$ The Drug Abuse Warning Network (DAWN) report for 2006 from the Substance Abuse and Mental Health Services Administration (SAMHSA) attributed 741,425 emergency room (ER) visits to the nonmedical use of prescription or over-the-counter pharmaceuticals or dietary supplements, accounting for $42.5 \%$ of the ER visits associated with drug misuse or abuse that year. ${ }^{44}$ Nonmedical use of hydrocodone or hydrocodone combinations was associated with 57,550 ER visits, similar to the 64,888 ER visits associated with nonmedical use of oxycodone or oxycodone combinations. ${ }^{44}$ Data from 8 poison control centers over 12 months in 2003 indicated that hydrocodone and oxycodone were involved in numerous reports involving opioid abuse and misuse..$^{45}$ In addition, data from the Centers for Disease Control and Prevention (CDC) indicate that in 2006, $37 \%$ of poison-related deaths involved opioids. ${ }^{46}$ 


\begin{tabular}{l|l}
\hline \multicolumn{1}{c|}{ TABLE 1) } & \multicolumn{1}{c}{ Selected Definitions of Terms Related to the Use and Abuse of Opioids for Pain Treatment } \\
\hline Term & \multicolumn{1}{c}{ Definition } \\
\hline Addiction & $\begin{array}{l}\text { "Addiction is a primary, chronic, neurobiologic disease, with genetic, psychosocial, and environmental factors influencing its development } \\
\text { and manifestations. It is characterized by behaviors that include the following: impaired control over drug use, craving, compulsive use, } \\
\text { and continued use despite harm." }\end{array}$ \\
\hline $\begin{array}{l}\text { Physical } \\
\text { dependence }\end{array}$ & $\begin{array}{l}\text { "Physical dependence is a state of adaptation that is manifested by drug class specific signs and symptoms that can be produced by abrupt } \\
\text { cessation, rapid dose reduction, decreasing blood level of the drug, and/or administration of an antagonist. Physical dependence, by itself, } \\
\text { does not equate with addiction." }\end{array}$ \\
\hline Tolerance & $\begin{array}{l}\text { "Tolerance is a physiologic state resulting from regular use of a drug in which an increased dosage is needed to produce a specific effect, } \\
\text { or a reduced effect is observed with a constant dose over time. Tolerance may or may not be evident during opioid treatment and does not } \\
\text { equate with addiction." }\end{array}$ \\
\hline Pseudoaddiction & $\begin{array}{l}\text { "The iatrogenic syndrome resulting from the misinterpretation of relief-seeking behaviors as though they are drug-seeking behaviors that } \\
\text { are commonly seen with addiction. The relief-seeking behaviors resolve upon institution of effective analgesic therapy." }\end{array}$ \\
\hline aDerived from Federation of State Medical Boards of the United States, Inc.42
\end{tabular}

\section{Factors Contributing to a Rise in Opioid Abuse}

A variety of factors have contributed to the increased abuse of opioids. Increasing volume of opioid prescriptions is a primary factor that influences availability and diversion for nonmedical use. ${ }^{8}$ A 2007 survey conducted by the National Institute on Drug Abuse (NIDA) revealed that of respondents in the 12th grade who reported inappropriate use of prescription opioids, approximately $70 \%$ were obtained from a friend or family member. ${ }^{47}$ Other means for obtaining opioids illicitly include purchasing them on the Internet or from a drug dealer. Additionally, in 2005, the DEA documented that 1.8 million doses of opioids were stolen from pharmacies or in truck hijackings. ${ }^{48}$

Abuse can be promoted by iatrogenic effects, such as cravings, withdrawal, and euphoria, all of which reinforce the use of opioids. The type of formulation and opioid receptor binding affinity can affect the level of euphoria, leading to reinforcement. By tampering with products for an alternative route of administration (e.g., intravenous injection or nasal snorting) abusers attain rapid increases in opioid plasma concentrations, which produce faster and more intense euphoric experiences.

\section{Opioid Diversion}

Prescription drug diversion, defined as the unlawful transferring of regulated pharmaceuticals from legal sources to the illicit marketplace, serves as the primary source of obtaining pain prescriptions illegally. ${ }^{49}$ Diversion can occur at any point in the drug distribution process, from theft at the manufacturing site to the act of transfer between patients. The 2008 annual report from the National Forensic Laboratory Information System noted that 7 opioids were among the top 25 drugs analyzed by forensic laboratories following police confiscation..$^{50}$ The opioids listed include hydrocodone, oxycodone, methadone, morphine, buprenorphine, codeine, and hydromorphone..$^{50}$

Internet pharmacies, which began in 1999, have provided a readily available avenue for abusers to obtain drugs. A report by the Center on Addiction and Substance Abuse (CASA) identified 365 websites that advertised and/or sold controlled prescription drugs online during the first quarter of $2008 .^{51}$ While 2 of these Internet sites were registered pharmacies, $85 \%$ did not require a prescription for the sale of these drugs. In addition, half of the remaining websites only required a prescription to be faxed, possibly allowing abusers to forge prescriptions or use prescriptions multiple times. ${ }^{51}$

Another common diversion tactic is doctor shopping, whereby patients obtain multiple opioid prescriptions from different physicians, usually by exaggerating or fabricating symptoms. Many "shoppers" fill their prescriptions at multiple pharmacies to conceal their actions. Additionally, patients often seek physicians who are more likely to write prescriptions for opioids. However, it should also be noted that pseudoaddiction is a term that has been applied to apparent drug-seeking behaviors in patients who experience inadequate pain relief. ${ }^{42,52}$

\section{Opioid Use for Chronic Pain Management- Regulatory and Legal Issues}

State and federal agencies provide legal and regulatory standards for prescribing and dispensing opioids. State medical boards have the primary authority for regulating physician behavior. Multiple federal agencies contribute to the monitoring and risk management of controlled substances. The FDA monitors medications via review of clinical data to ensure accurate marketing of drugs, thereby ensuring that drugs are safe and effective for human consumption. ${ }^{53}$ The DEA's mission is to enforce the controlled substance laws and regulations, as well as to arrest any persons involved in the manufacturing or distribution of illegal substances. ${ }^{54}$ The SAMHSA works through various programs to provide effective mental health and substance abuse treatment resources, reduce and prevent the abuse of illegal drugs, and collect and analyze behavioral health data. ${ }^{55}$ The NIDA is responsible for conducting and disseminating research across a variety of fields in an effort 


\section{Review of Regulatory Programs and New Opioid Technologies in Chronic Pain Management: Balancing the Risk of Medication Abuse with Medical Need}

to improve drug abuse/addiction-related prevention, treatment, and policy..$^{56}$ The Office of National Drug Control Policy (ONDCP) is responsible for creating policies, strategies, and priorities for the U.S. drug control policy. ${ }^{57}$

In the early 1990s, studies of the state medical boards indicated that they did not conform to current standards of practice in pain treatment and that the boards' actions may have penalized doctors who were prescribing controlled substances appropriately. ${ }^{58}$ In 1997, the Federation of State Medical Boards (FSMB) assembled pain, substance abuse, and regulatory experts to develop Model Guidelines for the Use of Controlled Substances for the Treatment of Pain. ${ }^{42,59}$ The DEA endorses the FSMB guidelines in anticipation that they will help physicians adhere to pain management standards and help law enforcement officials determine whether pain medication is being appropriately prescribed..$^{59}$ The FSMB guidelines, updated in 2004, recognized controlled substances as appropriate for the treatment of pain, encouraged physicians to adequately treat pain with opioids, addressed physicians' fears of regulatory scrutiny, and supported the concept of physicians maintaining appropriate and updated education about pain management. ${ }^{59}$ The FSMB also made recommendations regarding practice management including, but not limited to, documentation, informed consent, monitoring, and adherence to state and federal laws. ${ }^{59}$ The FSMB guidelines include a provision that physicians will not be judged solely on the basis of the amount of medication or length of treatment of pain with controlled substances. As of April 2010, the FSMB website reported 24 state medical boards that had adopted all or part of model guidelines. ${ }^{60}$

The Controlled Substance Act (CSA) is a federal statute under which the DEA enforces the regulation of the manufacture, importation, possession, use, and distribution of certain substances ${ }^{61}$ Drugs with addictive properties are listed on a schedule depending on their level of risk and medical usefulness. Schedule I drugs, including heroin and marijuana, are considered to be without medical benefit and may not be prescribed in clinical practice. Schedules II through V list medications with legitimate medical uses according to abuse risk. With regards to legally appropriate medications, the DEA has been working with FDA and other agencies to ensure an adequate supply is readily available to meet the legitimate needs of patients, while at the same time working to reduce the diversion, abuse, and misuse of these drugs. ${ }^{62}$

The U.S. Food and Drug Administration Amendments Act of 2007 granted the FDA the authority to require the submission and implementation of a Risk Evaluation and Mitigation Strategies (REMS) program if it determines that a drug's benefits outweigh its risks. ${ }^{63}$ The components of the REMS program include, but are not limited to, a plan for communicating a drug's serious risks; elements to guarantee safe use (e.g., specialty training and/or certification for providers and pharmacies); an implementation system to monitor REMS utilization; and a timetable for which these elements must be incorporated. ${ }^{63}$ Approved REMS for particular drugs may require patients to enroll in a registry or subject to monitoring in order to provide evidence or documentation of safe use conditions. ${ }^{63}$

\section{Strategies to Reduce the Burden of Opioid Abuse}

Opioid abuse is a complex problem that requires a multifaceted management strategy that engages many organizations and professionals, including state and federal governments, pharmaceutical companies, physicians, and pharmacists. Education of providers is an important mechanism to reduce opioid abuse; a 2005 survey indicated that only about one-half of pharmacists and one-fifth of physicians reported having received training on identifying prescription drug diversion. ${ }^{64}$

In order to reduce the incidence of opioid abuse among patients seeking pain relief, and to thwart abusers with hidden agendas from obtaining opioids from physicians, several methods can be utilized. The first is proper patient assessment for the initiation of opioid therapy. Recommendations from the APS and American Academy of Pain Medicine include conducting a thorough history and physical exam inclusive of psychosocial factors, family history, and risk assessment. ${ }^{65}$ A comprehensive benefit-to-harm assessment should also be conducted, and the appropriate diagnostic analysis should be performed to determine an underlying cause of the pain, including possible physical and psychological etiologies. ${ }^{65}$ Patients with somatoform pain disorder tend to provide vague complaints of pain regarding location and sensation. ${ }^{66}$

Risk stratification tools may help physicians determine which patients are at a higher risk of developing an addiction to opioids or are possibly misusing their medications. The revised Screener and Opioid Assessment for Patients in Pain (SOAPP-R) and Opioid Risk Tool (ORT) are predictive tools to assess the risk of developing aberrant behaviors for chronic pain patients being considered for long-term opioid therapy ${ }^{67,68}$ The Screening Instrument for Substance Abuse Potential (SISAP) assesses the possible substance abuse history of a patient prior to treatment, and the Diagnosis, Intractability, Risk, Efficacy (DIRE) questionnaire can be utilized to assess the potential benefit and harm of opioid treatment for a given patient. ${ }^{69,70}$

Once initiated on opioids, patients should be regularly monitored for treatment efficacy, movement towards treatment goals, improvements in functionality and quality of life measures, adverse events, aberrant behaviors, and medication adherence. Aberrant behaviors include doctor shopping, unauthorized self-increased dosing, drug hoarding, requesting specific drugs, and aggressively demanding higher dosages. ${ }^{71}$ Behaviors that are more predictive of drug abuse/misuse/ diversion include forging prescriptions, stealing drugs, using alternative methods of ingestion such as snorting or injecting 


\section{Review of Regulatory Programs and New Opioid Technologies in Chronic Pain Management: Balancing the Risk of Medication Abuse with Medical Need}

oral drugs, recurrent prescription losses, and simultaneous use of illicit drugs. ${ }^{71}$

For high-risk patients or those displaying aberrant behaviors, random urinalysis and pill counts can help to monitor adherence and possible diversion. ${ }^{71}$ One example of this monitoring involves patients on opioid therapy who show no opioids in their systems through urinalysis; these patients might be diverting their opioids rather than taking them. Urinalysis and pill count methods can also be used in low-risk patients to monitor adherence. The Current Opioid Misuse Measure (COMM) and the Pain Assessment and Documentation Tool (PADT) can be used to assess patients currently on opioid therapy who may be exhibiting aberrant behaviors associated with misuse of opioid medications. ${ }^{72,73}$

\section{Prescription Drug Monitoring Programs to Thwart Doctor Shopping.}

In recent years, state-specific PDMPs have been established in an attempt to reduce prescription drug diversion. ${ }^{74}$ As of January 2009, 38 states had laws to establish PDMPs, 32 of which were operational. ${ }^{75}$ These monitoring programs collect and analyze statewide data regarding the prescribing, dispensing, and use of prescription drugs in real time. The data can assist state law enforcement and regulatory groups in identifying possible illegal prescribing, dispensing, and acquisition of controlled substances.

PDMPs consist of 3 main components: (a) collection of prescription data from physicians and pharmacists, (b) storage and processing of the data, and (c) establishment of regulations to determine who can access the data. ${ }^{76}$ States vary regarding the specifics of their PDMPs, including details of who must provide data and what data are required, which schedule(s) of drugs are to be monitored, how often the data are collected, and who can access the prescription information. Typically, law enforcement agencies with appropriate documentation (e.g., a warrant) and licensure boards can access the data in association with ongoing investigations, and physicians and pharmacists can access data on their own patients. ${ }^{76}$ The purpose of allowing physicians and pharmacists access to data within PDMPs is to prevent abuse or diversion by identifying patients who may be doctor shopping.

PDMPs can be used as a reactive or proactive system, with most states using a reactive system. States such as Maine have PDMPs that are capable of delivering both reactive and proactive reports. As a reactive system, information about a potential abuser is produced only following an inquiry made by a prescriber or managed care organization. ${ }^{77}$ In proactive systems, state program personnel regularly review records to identify any suspicious activities and generate unsolicited reports that are then forwarded to physicians, pharmacists, and regulatory agencies in an effort to reduce diversion before it occurs (e.g., before a prescription is filled at a pharmacy). ${ }^{77}$ A 2006 survey of 262 prescribers in Maine who had received an unsolicited report found that $42.1 \%$ confirmed that the patient was misusing prescriptions, suggesting that prescribers were using the unsolicited reports in the way that the designers of proactive PDMPs intended.$^{78}$ In the same survey, only 3 of 354 prescribers $(0.8 \%)$ did not find the PDMP useful in helping "clinicians and pharmacies to monitor patients' controlled substance prescriptions," and only 6 (1.7\%) did not find the PDMP useful in controlling "doctor shopping" to obtain controlled substances. ${ }^{78}$ For the 34 pharmacy providers ("dispensers") who responded to the survey, only 1 (2.9\%) did not find the PDMP useful in helping clinicians and pharmacies to monitor controlled substance prescriptions and control "doctor shopping" to obtain controlled substances. ${ }^{78}$

The U.S. General Accountability (formerly, Accounting) Office (2002) found that while a PDMP may reduce diversion within the state in which it is used, an increase in diversion among surrounding states without PDMPs may occur. ${ }^{74}$ Accordingly, the U.S. Department of Justice, the Integrated Justice Information Systems (IJIS Institute), and other groups have collaborated on the PDMP Information Exchange (PMIX) project, which assists in the exchange of prescription information between states. ${ }^{79}$ This interstate communication may reduce the number of patients who doctor shop across state lines. The presence of PDMPs in all 50 states would increase the effectiveness of PMIX programs and further reduce doctor shopping across state lines.

The U.S Government Accountability Office (GAO) also reported that in Kentucky, the incorporation of a PDMP reduced the average time necessary for regulatory agencies to conduct investigations of possible diversion from 156 days to 16 days. ${ }^{76}$ Furthermore, only 2 of the 10 states with the greatest number of OxyContin prescriptions had operational PDMPs, compared with 6 of the 10 states with the fewest prescriptions for this drug. ${ }^{76}$

\section{New Drug Formulations Intended to Deter Abuse}

To address the serious public health concerns of opioid abuse and diversion, new formulations are being developed with the goal of reducing the attractiveness and drug-liking qualities of conventional opioid formulations. The new technologies are designed to hinder the extraction of active ingredients and to thereby control their bioavailability and prevent administration through alternative routes (Table 2). There are 3 main categories of new abuse-deterring technologies: (a) physical barrier mechanisms, which are designed to inhibit manual and chemical extraction of active substances; (b) agonist-antagonist formulations, which release opioid antagonist agents when abusers tamper with products; and (c) aversive substances, which release agents that cause unpleasant side effects when abusers consume opioid products in excess. ${ }^{80}$ 


\section{Review of Regulatory Programs and New Opioid Technologies in Chronic Pain Management:}

Balancing the Risk of Medication Abuse with Medical Need

\section{TABLE 2 New Formulations Designed to Deter Opioid Abuse}

\begin{tabular}{|c|c|c|}
\hline Trade and/or Research Name & Formulation and Description of Product & Status \\
\hline Embeda & $\begin{array}{l}\text { Encapsulated beads of ER morphine sulfate (range } 20 \mathrm{mg} \text { to } 100 \mathrm{mg} \text { ) } \\
\text { with a sequestered core of naltrexone } \mathrm{HCl} \text { (range } 0.8 \mathrm{mg} \text { to } 4 \mathrm{mg} \text { ) }\end{array}$ & August 13, 2009: approved by FDA ${ }^{85}$ \\
\hline EXALGO & $\begin{array}{l}\text { Tablets containing ER hydromorphone } \mathrm{HCl}(8 \mathrm{mg}, 12 \mathrm{mg}, 16 \mathrm{mg}) \text {; uses } \\
\text { OROS rate-controlling membrane and osmotic delivery system }\end{array}$ & March 1, 2010: approved by FDA 84 \\
\hline OxyContin & $\begin{array}{l}\text { ER oxycodone } \mathrm{HCl}(10 \mathrm{mg}, 15 \mathrm{mg}, 20 \mathrm{mg}, 30 \mathrm{mg}, 40 \mathrm{mg}, 60 \mathrm{mg}, 80 \\
\mathrm{mg} \text { ) tablets designed to resist fracturing and to produce a gel substance } \\
\text { when exposed to solvents }\end{array}$ & April 5, 2010: approved by FDA ${ }^{83}$ \\
\hline Acurox & $\begin{array}{l}\text { Tablet containing IR oxycodone } \mathrm{HCl}(5 \mathrm{mg} \text { and } 7.5 \mathrm{mg} \text { ) and niacin ( } 30 \\
\mathrm{mg} \text { ) as an aversive substance; uses proprietary (Aversion) technology } \\
\text { intended to prevent snorting and intravenous injection }\end{array}$ & $\begin{array}{l}\text { April 22, 2010: FDA Anesthetic and Life Support } \\
\text { Drugs and Drug Safety and Risk Management } \\
\text { committees voted not to recommend approval } \\
\text { based on insufficient evidence }\end{array}$ \\
\hline $\begin{array}{l}\text { Remoxy } \\
\text { (PTI-821) }\end{array}$ & $\begin{array}{l}\text { ER oxycodone ( } 5 \text { to } 40 \mathrm{mg} \text { ) encapsulated in a viscous gel matrix; using } \\
\text { proprietary (ORADUR) technology }\end{array}$ & $\begin{array}{l}\text { December 12, 2008: FDA issued CRL outlining } \\
\text { additional requirements for approving NDA }{ }^{96}\end{array}$ \\
\hline COL-003 & $\begin{array}{l}\text { ER oxycodone; uses a proprietary technology (DETERx) which encap- } \\
\text { sulates the active ingredient in a microparticle matrix }\end{array}$ & $\begin{array}{l}\text { June 10, 2009: submitted proposal to FDA for a } \\
\text { Phase III pivotal clinical trial }{ }^{97}\end{array}$ \\
\hline
\end{tabular}

$C R L=$ complete response letter; $E R=$ extended release; $F D A=U$.S. Food and Drug Administration; $I R=$ immediate release; $m g=$ milligram; $N D A=n e w$ drug application; OROS = osmotically-controlled release oral delivery system.

The FDA has made clear that new products intended to deter misuse and abuse will not be able to make a claim of "abuse resistance" in product labeling or marketing in the absence of data from long-term epidemiologic studies that show actual reduction in "abuse and addiction and the consequences of those behaviors." ${ }^{81}$ However, the FDA also recognizes that long-term surveillance data will not be available for some time and in the interim has stated that it would allow inclusion in the label of the physiochemical features of the product if there are "sufficient data indicating that the formulation would be resistant to manipulation." ${ }^{81}$ Among the specific concerns are the creation of a false sense of security contributing to less conservative prescribing. ${ }^{82}$

In April 2010, the FDA approved a new formulation of OxyContin that cannot be crushed or otherwise reduced to a particle size that would permit snorting, and the new formulation of OxyContin will replace the current formulation. ${ }^{83}$ However, despite the expectation that the new formulation would deter abuse of OxyContin, the FDA did not permit label or marketing claims of safety or abuse deterrence and required the manufacturer to use the REMS that was developed for hydromorpone ER (Exalgo) that was approved on March 1, 2010, by the FDA. ${ }^{84}$

\section{Combinations with the Opioid Antagonist Naltrexone}

Naltrexone, an opioid antagonist, is being studied in combination with opioids such as morphine or oxycodone as an abuse-deterrent formulation. Taken whole, the naltrexone remains intact, passes through the gastrointestinal tract without being absorbed, and does not affect the analgesic potential of the opioid. However, if crushed, chewed, or chemically manipulated, the naltrexone is released, which causes competitive binding at the mu-opioid receptors and inhibition of the euphoric effects of the opioid. ${ }^{80}$

The FDA approved extended-release morphine sulfate (ERMS) in combination with naltrexone (Embeda) on August 13, 2009, the first of the new opioid formulations to gain approval (Table 2) ${ }^{85}$ Preliminary clinical trials yielded the following outcomes for comparisons of ERMS with naltrexone and conventional opioid formulations ingested intact: (a) bioequivalent opioid availability for ERMS alone and ERMS with naltrexone; (b) negligible plasma concentrations of naltrexone in a small percentage of subjects who ingested ERMS with naltrexone capsules, indicating that the antagonist largely remains sequestered in normal use; and (c) a 30\% or greater reduction in morphine-induced euphoria for more than 50\% of subjects who received naltrexone with immediate-release morphine sulfate (MSIR) compared with subjects who received MSIR alone. ${ }^{86}$ In comparisons of whole and crushed formulations of ERMS with naltrexone, scores for subject-reported euphoria and drug-liking did not differ significantly. The latter result suggests that the new formulation has the potential to deter abuse because its manipulation through crushing was not associated with an increase in euphoria and drug-liking. However, the FDA advisory committee in its meeting to review the new drug application for ERMS with naltrexone expressed concern that the new formulation would not prevent extraction of morphine sulfate (for intravenous administration) that would exclude naltrexone. ${ }^{87}$ For this reason, the FDA prohibited the marketing of this product with a claim that there is a reduction in the risk of abuse.

\section{Combinations with Aversive Agents}

The addition of aversive substances to opioid formulations may limit abuse potential by creating an unpleasant effect if the product is taken at a higher-than-recommended dose, or 


\section{Review of Regulatory Programs and New Opioid Technologies in Chronic Pain Management: Balancing the Risk of Medication Abuse with Medical Need}

if the product is tampered with. An immediate-release oxycodone formulation has been developed (Acurox, Table 2) that contains subtherapeutic levels of niacin. ${ }^{88}$ This formulation also incorporates a technology, called Aversion, that employs gelling ingredients to deter intravenous injection of dissolved tablets and nasal snorting of crushed tablets. ${ }^{89}$ When taken in small doses, niacin produces no negative effects..$^{90}$ However, when niacin is taken in large amounts (more than 300 milligrams $[\mathrm{mg}]$ ), it may cause flushing, itching, sweats, chills, and a feeling of discomfort that lasts for 1 to 3 hours. ${ }^{80}$ Results from a manufacturer-conducted clinical trial on the niacin-containing oxycodone product indicated that it (a) provided significantly greater analgesia than a placebo, (b) did not affect the safety profile of oxycodone, (c) reduced drug-liking effects of oxycodone in direct proportion to the amount of niacin consumed, and (d) increased disliking scores/aversion compared with oxycodone $\mathrm{HCl} .{ }^{90}$ An important factor in the abuse potential of a drug is the ability to extract the pure oxycodone from the formulation. Extraction tests revealed that only trace amounts of oxycodone could be extracted from the niacin-containing product in approximately 6 hours, making it unattractive to users seeking a "quick high." Similar analysis of currently available oxycodone formulations resulted in extraction of approximately $80 \%$ oxycodone in less than 10 minutes. ${ }^{88}$

The FDA advisory committees (Anesthetic and Life Support Drugs Advisory Committee and Drug Safety and Risk Management Advisory Committee) met jointly on April 22, 2010, to consider NDA 22-451 for this new formulation of oxycodone (Acurox), "the first immediate-release opioid since Talwin Nx." ${ }^{81}$ The committees voted against recommending approval, concluding that insufficient evidence is available to support claims that the niacin formulation has abuse-deterring effects. ${ }^{91}$ In addition to opioid formulations that incorporate niacin, other aversive agents include unpleasant odor- and taste-altering agents and capsaicin, which induces a burning sensation when the product is crushed or dissolved and then taken through alternative methods. ${ }^{82}$

\section{Gel-Based Matrix}

PTI-821 (trade name Remoxy) is controlled-release oxycodone suspended in a water-insoluble, highly viscous matrix with a hard gelatin outer capsule. The manufacturer is seeking approval for dosage strengths ranging from $5 \mathrm{mg}$ to $40 \mathrm{mg}{ }^{92}$ When swallowed whole, PTI-821 and controlled-release oxycodone yielded similar plasma oxycodone levels, but when crushed and taken with either water or alcohol, PTI-821 yielded lower plasma oxycodone concentrations compared with controlled-release oxycodone treated in the same manner. ${ }^{93}$ Patients with moderate-to-severe osteoarthritis of the knee or hip who were given PTI-821 reported a 30\% reduction in pain intensity after 5 weeks of treatment compared with a $20 \%$ reduction in pain intensity for patients given placebo $(P=0.043) .{ }^{94}$
Another barrier formulation, designated COL-003 for research purposes, has a patented design that encapsulates sustained-release oxycodone in fatty/waxy particles. The "micro-particles" resist chewing and crushing, thereby deterring extraction of opioid substances and dose dumping through alternative routes of administration. Assessing the safety and pharmacokinetics of COL-003, Fleming et al. (2008) found that the formulation maintained its sustained-release properties in various tampering conditions.$^{95}$ Moreover, plasma concentrations of oxycodone were bioequivalent for chewed versus intact COL-003 formulations, indicating that abusers would not achieve their objective of a rapid high through tampering with the capsule.

\section{Conclusions}

Opioid therapy is an important element in pain management programs for patients with legitimate chronic pain that does not respond to preliminary treatments. However, a balance is essential to prevent opioid abuse and diversion. In addition, clinicians must apply diagnostic procedures to identify patients who would benefit from or require referral to appropriate specialists. The various strategies for treating chronic pain effectively and, at the same time, deterring opioid abuse and diversion involve proper patient assessment and diagnosis, risk stratification, and regular monitoring. Unfortunately, opioid abusers have discovered ways to bypass the regulatory systems and obtain drugs through doctor shopping, feigning pain, and utilizing Internet pharmacies. A multidisciplinary approach that includes state and federal prescription monitoring programs in conjunction with new abuse-deterrent drug formulations may contribute to curtailing opioid abuse and diversion in the future.

\section{Authors}

DAVID FISHBAIN, MD, FAPA, is Professor of Psychiatry and Adjunct Professor of Neurological Surgery and Anesthesiology at the Miller School of Medicine at the University of Miami, Miami VAH and Rosomoff Comprehensive Pain and Rehabilitation Center in Miami, Florida. SANDRA JOHNSON, JD, LLM, is Professor Emerita of Health Law and Ethics at Saint Louis University Center for Health Care Ethics in St. Louis, Missouri. LYNN WEBSTER, MD, FACPM, FASAM, is co-founder and Medical Director of Lifetree Clinical Research and Pain Clinic and co-founder of LifeSource, Salt Lake City, Utah. LAURENCE GREENE, PhD, is Senior Medical Writer, and JOANNE FAYSAL, BS, is Medical Writer, PRIME, Tamarac, Florida.

AUTHOR CORRESPONDENCE: David Fishbain, MD, FAPA, Rm 3302, Miller School of Medicine at the University of Miami, Mental Health Hospital Center, 1695 N.W. 9th Ave., Miami, FL 33136. Tel.: 305.243.4060; E-mail:DFishbain@med.miami.edu. 


\section{Review of Regulatory Programs and New Opioid Technologies in Chronic Pain Management: Balancing the Risk of Medication Abuse with Medical Need}

\section{DISCLOSURES}

This manuscript was funded by King Pharmaceuticals. David Fishbain reported serving as a consultant and a member of the speakers bureau for Eli Lilly. Sandra Johnson reported compensation for participation in this project. Lynn Webster reported serving as a consultant for Cephalon, Medtronic, King Pharmaceuticals, and Ameritox; service on advisory boards for Ameritox, King Pharmaceuticals, Nektar, Nervo, Neuromed, and Purdue; and receipt of research grants from Advanced Biotic, Arcion, Cephalon, CoMentis, Forest, Hisamitsu, Hoffman LaRoche, King Pharmaceuticals, Medtronic, Merck, Myriad, Nektar, NeurogesX, Wyeth, and Xenoport.

Fishbain, Johnson, and Webster performed the data collection and interpretation of the medical literature. Faysal wrote and revised the manuscript with assistance of the other authors. Greene and Faysal revised the manuscript with the assistance of the other authors.

\section{REFERENCES}

1. National Institutes of Health. NIH guide. New directions in pain research. September 4, 1998. Available at: http://grants.nih.gov/grants/guide/pa-files/ PA-98-102.html. Accessed April 24, 2010.

2. National Headache Foundation. Headache topic sheet: migraine. 2010 Available at: http://www.headaches.org/education/Headache_Topic_Sheets/ Migraine. Accessed April 24, 2010.

3. National Center for Health Statistics. Health, United States, 2006 with chartbook on trends in the health of Americans. November 2006. Available at: www.cdc.gov/nchs/data/hus/hus06.pdf. Accessed April 24, 2010.

4. National Center for Chronic Disease Prevention and Health Promotion. Arthritis: data and statistics. Available at: http://www.cdc.gov/ARTHRITIS/ data_statistics/arthritis_related_statistics.htm. Accessed April 24, 2010.

5. Helmick CG, Felson DT, Lawrence RC, et al. Estimates of the prevalence of arthritis and other rheumatic conditions in the United States. Part I. Arthritis Rheum. 2008;58(1):15-25. Available at: http://www3.interscience. wiley.com/cgi-bin/fulltext/117874817/PDFSTART. Accessed April 24, 2010

6. Lawrence RC, Felson DT, Helmick CG, et al. Estimates of the prevalence of arthritis and other rheumatic conditions in the United States. Part II. Arthritis Rheum. 2008;58(1):26-35. Available at: http://www3.interscience. wiley.com/cgi-bin/fulltext/117874826/PDFSTART. Accessed April 24, 2010.

7. National Fibromyalgia Association. About fibromyalgia. Available at: http://www.fmaware.org/site/PageServer?pagename=fibromyalgia_affected. Accessed April 24, 2010.

8. Kuehn BM. Opioid prescriptions soar: increase in legitimate use as well as abuse. JAMA. 2007;297(3):249-51.

9. Strassels SA. Economic burden of prescription opioid misuse and abuse. J Manag Care Pharm. 2009;15(7):556-62. Available at: http://www.amcp.org/ data/jmcp/556-562.pdf.

10. White AG, Birnbaum HG, Mareva MN, et al. Direct costs of opioid abuse in an insured population in the United States. J Manag Care Pharm. 2005;11(6):469-79. Available at: http://www.amcp.org/data/jmcp/3.pdf.

11. IASP Task Force of Taxonomy. Part III: Pain terms, a current list with definitions and notes on usage. In: Merskey H, Bogbuk N, ed. Classification of Chronic Pain. Seattle, WA: IASP Press; 1994:209-14

12. Johnson Wright LJ, Afari N, Zautra A. The illness uncertainty concept: a review. Curr Pain Headache Rep. 2009;13(2):133-38.

13. Fishbain DA, Bruns D, Disorbio JM, Lewis JE, Gao J. Exploration of the illness uncertainty concept in acute and chronic pain patients vs community patients. Pain Med. In press.

14. American Psychiatric Association. Diagnostic and Statistical Manual of Mental Disorders 4th ed. Washington, DC: American Psychiatric Association; 2000

15. Morgan GE Jr, Mikhail MS, Murray MJ. Pain management. In: Morgan GE Jr, Mikhail MS, Murray MJ, eds. Clinical Anesthesiology. New York: McGraw-Hill; 2006:389-412.
16. Strang P, Strang S, Hultborn R, Arnér S. Existential pain-an entity, a provocation, or a challenge? J Pain Symptom Manage. 2004;27(3):241-50.

17. Jage J. Opioid tolerance and dependence-do they matter? Eur J Pain. 2005;9(2):157-62.

18. Wambach S, Rohr P, Häuser W. Abuse of opioid therapy in somatoform pain disorder. A contribution from a psychosomatic/pain therapist point of view to the discussion of the indication of opioids in nonmalignant pain based on 8 cases. Schmerz. 2001;15(4):254-64.

19. Scholz J, Woolf CJ. Can we conquer pain? Nat Neurosci. 2002;5 Suppl:1062-67.

20. Woolf CJ. Pain: moving from symptom control toward mechanismspecific pharmacologic management. Ann Intern Med. 2004;140(6):441-51 Available at: http://www.annals.org/cgi/reprint/140/6/441.pdf. Accessed April 24, 2010.

21. Woolf CJ, Doubell TP. The pathophysiology of chronic pain-increased sensitivity to low threshold A beta-fibre inputs. Curr Opin Neurobiol. 1994:4(4):525-34

22. Basbaum AI, Jessel TM. The perception of pain. In: Kandel ER, Schwatrz JH, Jessel TM, eds. Principles of Neural Science. New York: McGraw-Hill; 2000:472-91.

23. Baron R. Mechanisms of disease: neuropathic pain-a clinical perspective. Nat Clin Pract Neurol. 2006;2(2):95-106. Available at: http://www. nature.com/nrneurol/journal/v2/n2/pdf/ncpneuro0113.pdf. Accessed April 24, 2010.

24. Chong MS, Bajwa ZH. Diagnosis and treatment of neuropathic pain. $J$ Pain Symptom Manage. 2003;25(5 Suppl):S4-S11.

25. Woolf CJ, Ma Q. Nociceptors-noxious stimulus detectors. Neuron. 2007;55(3):353-64. Available at: http://www.sciencedirect.com/science?_ob=MImg\&_imagekey=B6WSS-4PB1JGW-5-1\&_cdi=7054\&_ user $=4420034 \&$ \& pii $=$ S0896627307005375\&_orig $=$ search $\varepsilon_{-}$ coverDate $=08 \% 2$ F02\%2F2007\&_sk=999449996\&view $=c \& w c h p=d G L b V l z-$ zSkWb\&md5=39e54a84638f17b918dbf03f722cb00e\&ie=/sdarticle.pdf. Accessed April 24, 2010.

26. Lynch ME. The pharmacotherapy of chronic pain. Rheum Dis Clin North Am. 2008;34(2):369-85.

27. Messing RO. Nervous system disorders. In: McPhee SJ, Ganong WF, eds. Pathophysiology of Disease. New York: McGraw-Hill; 2006:144-87.

28. Kennedy JD. Neuropathic pain: molecular complexity underlies continuing unmet medical need. J Med Chem. 2007;50(11):2547-56.

29. Wolfe F, Smythe HA, Yunus MB, et al. The American College of Rheumatology 1990 criteria for the classification of fibromyalgia. Report of the multicenter criteria committee. Arthritis Rheum. 1990;33(2):160-72.

30. Mannion RJ, Woolf CJ. Pain mechanisms and management: a central perspective. Clin J Pain. 2000;16(3 Suppl):S144-S56.

31. Fields HL, Martin JB. Pain: pathophysiology and management. In: Fauci AS, Braunweld E, Kasper DL, Hauser SL, Longo DL, Jameson JL, eds Harrison's Principles of Internal Medicine. New York: McGraw-Hill; 2008.

32. Petersen-Felix S, Curatolo M. Neuroplasticity-important factor in acute and chronic pain. Swiss Med Wkly. 2002;132(21-22):273-78. Available at: http://www.smw.ch/docs/pdf200x/2002/21/smw-09913.pdf. Accessed April 24, 2010

33. Blackburn-Munro G, Blackburn-Munro RE. Chronic pain, chronic stress and depression: coincidence or consequence? J Neuroendocrinol. 2001;13(12):1009-23.

34. Woolf CJ, Salter MW. Neuronal plasticity: increasing the gain in pain Science. 2000;288(5472):1765-69.

35. Fishbain DA. Polypharmacy treatment approaches to the psychiatric and somatic comorbidities found in patients with chronic pain. Am J Phys Med Rehabil. 2005;84(3 Suppl):S56-S63. 


\section{Review of Regulatory Programs and New Opioid Technologies in Chronic Pain Management: Balancing the Risk of Medication Abuse with Medical Need}

36. Fishbain DA, Cole B, Lewis J, Rosomoff HL, Rosomoff RS. What percentage of chronic nonmalignant pain patients exposed to chronic opioid analgesic therapy develop abuse/addiction and/or aberrant drug-related behaviors? A structured evidence-based review. Pain Med. 2008;9(4):444-59.

37. Gallagher RM. Rational integration of pharmacologic, behavioral, and rehabilitation strategies in the treatment of chronic pain. Am J Phys Med Rehabil. 2005;84(3 Suppl):S64-S76.

38. Goldenberg DL, Burckhardt C, Crofford L. Management of fibromyalgia syndrome. JAMA. 2004;292(19):2388-95. Available at: http://jama.ama-assn. org/cgi/reprint/292/19/2388. Accessed April 24, 2010.

39. Phillips KA. Pain disorder (somatoform pain disorder). Merck.com. June 2008. Available at: http://www.merck.com/mmpe/sec15/ch204/ch204f. html\#sec15-ch204-ch204f-807. Accessed April 25, 2010.

40. Manchikanti L, Singh A. Therapeutic opioids: a ten-year perspective on the complexities and complications of the escalating use, abuse, and nonmedical use of opioids. Pain Physician. 2008;11(2 Suppl):S63-S88. Available at: http://www.painphysicianjournal.com/2008/march/2008;11;S63-S88.pdf. Accessed April 24, 2010

41. Drug Enforcement Administration Office of Diversion Control. ARCOS: retail drug summary 1997-2006. Available at: http://www.deadiversion. usdoj.gov/arcos/retail_drug_summary/index.html. Accessed April 25, 2010

42. Federation of State Medical Boards of the United States, Inc. Model policy for the use of controlled substances for the treatment of pain. May 2004 Available at: http://www.fsmb.org/pdf/2004_grpol_Controlled_Substances. pdf. Accessed April 25, 2010.

43. Substance Abuse and Mental Health Services Administration, Office of Applied Studies. Results from the 2008 National Survey on Drug Use and Health: National Findings. (Office of Applied Studies, NSDUH Series H-36, DHHS Publication No. SMA 09-4434). Rockville, MD. 2009. Available at: www.oas.samhsa.gov/nsduh/2k8nsduh/2k8Results.pdf. Accessed April 25, 2010.

44. Substance Abuse and Mental Health Services Administration, Office of Applied Studies. Drug Abuse Warning Network, 2006: national estimates of drug-related emergency department visits. (Office of Applied Studies, DAWN Series D-30, DHHS Publication No. SMA 08-4339). Rockville, MD. August 2008. Available at: http://www.odmhsas.org/resourcecenter/ ResourceCenter/Publications/Current/2005.pdf. Accessed April 29, 2010.

45. Hughes AA, Bogdan GM, Dart RC. Active surveillance of abused and misused prescription opioids using poison center data: a pilot study and descriptive comparison. Clin Toxicol (Phila). 2007;45(2):144-51.

46. Warner M, Chen LH, Makuc DM. Increase in fatal poisonings involving opioid analgesics in the United States, 1999-2006. September 2009. Available at: http://www.cdc.gov/nchs/data/databriefs/db22.pdf. Accessed April 25, 2010.

47. Johnston LD, O'Malley PM, Bachman JG, Schulenberg JE. Monitoring the future national survey results on drug use, 1997-2007. Volume I: Secondary school students. National Institute on Drug Abuse. September 2008. Available at: http://monitoringthefuture.org/pubs/monographs/voll_2007. pdf. Accessed April 25, 2010.

48. Johnson SH. Regulatory and compliance aspects of pain management in managed care. Presented at: Managed Care Workgroup on Pain Management; May 1, 2009; Miami, FL.

49. Inciardi JA, Surratt HL, Kurtz SP, Cicero TJ. Mechanisms of prescription drug diversion among drug-involved club- and street-based populations. Pain Med. 2007;8(2):171-83.

50. National Forensic Laboratory Information System (NFLIS). Year 2008 Annual Report. Springfield, VA: Drug Enforcement Administration Office of Diversion Control; July 2009. Available at: http://www.deadiversion.usdoj. gov/nflis/2008annual_rpt.pdf. Accessed April 25, 2010.

51. Busko M. Internet trafficking of controlled prescription drugs remains extensive. July 18, 2008. Medscape Medical News. Available at: http://www. medscape.com/viewarticle/577728. Accessed April 25, 2010.
52. Weissman DE, Haddox JD. Opioid pseudoaddiction—an iatrogenic syndrome. Pain. 1989;36(3):363-66.

53. U.S. Food and Drug Administration. About FDA: centers \& offices. Available at: http://www.fda.gov/AboutFDA/CentersOffices/default.htm. Accessed April 25, 2010.

54. U.S. Drug Enforcement Administration. DEA mission statement. Available at: http://www.justice.gov/dea/agency/mission.htm. Accessed April 25, 2010 .

55. Substance Abuse and Mental Health Services Administration. About us: agency overview. Available at: http://www.samhsa.gov/About/background. aspx. Accessed April 25, 2010

56. National Institute on Drug Abuse. About NIDA: mission. Available at: http://www.drugabuse.gov/about/aboutnida.html. Accessed April 25, 2010.

57. Office of National Drug Control Policy. About. Available at: http://www. whitehousedrugpolicy.gov/about/index.html. Accessed April 25, 2010.

58. Johnson SH. Disciplinary actions and pain relief: analysis of the Pain Relief Act. J Law Med Ethics. 1996;24(4):319-27.

59. Joranson DE, Gilson AM, Dahl JL, Haddox JD. Pain management, controlled substances, and state medical board policy: a decade of change. J Pain Symptom Manage. 2002;23(2):138-47.

60. Federation of State Medical Boards. FSMB model policy. Available at: http://www.fsmb.org/grpol_pain_policy_resource_center.html. Accessed April 25, 2010.

61. U.S. Drug Enforcement Administration. Title 21—food and drugs. Chapter 13: Drug abuse prevention and control. Available at: http://www. justice.gov/dea/pubs/csa.html. Accessed April 25, 2010.

62. U.S. Drug Enforcement Administration. DEA congressional testimony. Status of the efforts of the FDA and DEA in regulating Schedule II prescription painkillers, specifically OxyContin and other opioid analgesics. September 13, 2005. Available at: http://www.justice.gov/dea/pubs/cngrtest/ ct091305.html. Accessed April 25, 2010.

63. U.S. Food and Drug Administration. Questions and answers on the federal register notice on drugs and biological products deemed to have risk evaluation and mitigation strategies. March 27, 2008 Available at: http://www.fda.gov/RegulatoryInformation/Legislation/ FederalFoodDrugandCosmeticActFDCAct/SignificantAmendments totheFDCAct/FoodandDrugAdministrationAmendmentsActof2007/ ucm095439.htm. Accessed April 25, 2010.

64. Young D. Pharmacists, physicians lack training to identify drug diversion, report says. American Society of Health-System Pharmacists. July 7, 2005. Available at: http://www.ashp.org/import/news/ HealthSystemPharmacyNews/newsarticle. aspx?id=1925. Accessed April 29, 2010.

65. Chou R, Fanciullo GJ, Fine PG, et al. Clinical guidelines for the use of chronic opioid therapy in chronic noncancer pain. J Pain. 2009;10(2):113-30.

66. Adler RH, et al. How not to miss a somatic needle in the haystack of chronic pain. J Psychosom Res. 1997;42(5):499-505.

67. Butler SF, Fernandez K, Benoit C, Budman SH, Jamison RN. Validation of the revised Screener and Opioid Assessment for Patients with Pain (SOAPP-R). J Pain. 2008;9(4):360-72.

68. Webster LR, Webster RM. Predicting aberrant behaviors in opioidtreated patients: preliminary validation of the Opioid Risk Tool. Pain Med. 2005;6(6):432-42.

69. Coambs RB, Jarry JL, Santhiapillai AC, Abrahamsohn RV, et al. The SISAP: a new screening instrument for identifying potential opioid abusers in the management of chronic nonmalignant pain within general medical practice. Pain Res Manage. 1996;1(3):155-62. Available at: http://www.pulsus. $\mathrm{com} /$ journals/abstract.jsp?jnlKy=7\&atlKy=2908\&isuKy=520\&isArt=t\&HCty pe $=$ Consumer. Accessed April 25, 2010

70. Belgrade MJ, Schamber CD, Lindgren BR. The DIRE score: predicting outcomes of opioid prescribing for chronic pain. J Pain. 2006;7(9):671-81. 


\section{Review of Regulatory Programs and New Opioid Technologies in Chronic Pain Management: Balancing the Risk of Medication Abuse with Medical Need}

71. Passik S, Portenoy RK, Ricketts PL. Substance abuse among cancer patients, part 1: prevalence and diagnosis. Oncology (Williston Park). 1998;12(4):517-21, 524.

72. Butler SF, Budman SH, Fernandez KC, et al. Development and validation of the current opioid misuse measure. Pain. 2007;130(1-2):144-56.

73. Passik SD, Kirsh KL, Whitcomb L, et al. Monitoring outcomes during long-term opioid therapy for noncancer pain: results with the pain assessment and documentation tool. J Opioid Manag. 2005;1(5):257-66.

74. U.S. General Accountability Office. Prescription drugs: state monitoring programs provide useful tool to reduce diversion. May 2002. Available at: http://www.gao.gov/new.items/d02634.pdf. Accessed April 25, 2010.

75. U.S. Department of Justice. National Drug Intelligence Center. National prescription drug threat assessment 2009. Available at: http://www.usdoj. gov/ndic/pubs33/33775/33775p.pdf. Accessed April 25, 2010.

76. Wang J, Christo PJ. The influence of prescription monitoring programs on chronic pain management. Pain Physician. 2009;12(3):507-15.

77. Simeone R, Holland L. An evaluation of prescription drug monitoring programs. September 1, 2006. Available at: http://www.simeoneassociates com/simeone 3.pdf. Accessed April 25, 2010.

78. Lambert D. Impact evaluation of Maine's prescription drug monitoring program. March 2007. Available at: http://www.maine.gov/dhhs/osa/data/ pmp/files/Reports/ME_PMP_IMPACT_EVAL_2007.pdf. Accessed April 25, 2010.

79. IJIS Institute. Prescription monitoring program (PMP). Available at: http://www.ijis.org/_programs/pdmp.html. Accessed April 25, 2010.

80. Webster L. Update on abuse-resistant and abuse-deterrent approaches to opioid formulations. Pain Med. 2009;10(Suppl 2):S124-S33.

81. U.S. Food and Drug Administration. Advisory committee meeting: background package (Acurox, NDA 22-451). April 22, 2010. Available at: http:// www.fda.gov/downloads/AdvisoryCommittees/CommitteesMeetingMaterials/ Drugs/AnestheticAndLifeSupportDrugsAdvisoryCommittee/UCM209141. pdf. Accessed April 25, 2010.

82. Katz N. Abuse-deterrent opioid formulations: are they a pipe dream? Curr Rheumatol Rep. 2008;10(1):11-18

83. U.S. Food and Drug Administration. NDA 022272 approval letter. OxyContin (oxycodone hydrochloride controlled-release) tablets. April 5, 2010. Available at: http://www.accessdata.fda.gov/drugsatfda_docs/ appletter/2010/022272s000ltr.pdf. Accessed April 25, 2010.

84. U.S. Food and Drug Administration. NDA 021217 approval letter. Exalgo (hydromorphone extended-release) tablets. March 1, 2010. Available at: http://www.accessdata.fda.gov/drugsatfda_docs/ appletter/2010/021217s000ltr.pdf. Accessed April 25, 2010.

85. U.S. Food and Drug Administration. NDA 22-321 approval letter. EMBEDA (morphine sulfate and naltrexone hydrochloride extended-release) capsules. August 13, 2009. Available at: http://www.accessdata.fda.gov/drugsatfda_docs/appletter/2009/022321s000ltr.pdf. Accessed April 25, 2010.
86. Alpharma Pharmaceuticals. ALO-01 (Morphine sulfate extended-release with sequestered naltrexone hydrochloride) capsules for the management of moderate to severe pain when a continuous, around-the-clock opioid analgesic is needed for an extended period of time. NDA 22-32. November 14 , 2008. Available at: http://www.fda.gov/ohrms/dockets/AC/08/briefing/20084395b2-02-ALPHARMA.pdf. Accessed April 25, 2010.

87. U.S. Food and Drug Administration. Final minutes: joint meeting of the Anesthetic and Life Support Drugs Advisory Committee and Drug Safety and Risk Management Advisory Committee. November 14, 2008. Available at: http://www.fda.gov/ohrms/dockets/ac/08/minutes/2008-4395m2-finalrevised.pdf. Accessed April 25, 2010.

88. Acura Pharmaceuticals. Acurox tablets. Available at: http://acurapharm. com/products/acurox-tablets. Accessed April 25, 2010.

89. Acura Pharmaceuticals. Aversion technology. Available at: http://acurapharm.com/research-development/aversion-technology. Accessed April 25, 2010 .

90. Jasinski DR. Evaluation for flushing, safety and tolerability of niacin (N) in combination with $40 \mathrm{mg}$ of oxycodone. Available at: http://acurapharm. com/investors/presentations-webcasts. Accessed April 25, 2010.

91. King Pharmaceuticals. Acura Pharmaceuticals and King Pharmaceuticals provide update on FDA advisory committee meeting for ACUROX. April 22, 2010. Available at: http://www.kingpharm.com/Investors/News_Details. cfm?news_item_id=552. Accessed April 25, 2010.

92. Pain Therapeutics, Inc. NDA 22-324. Remoxy XRT (oxycodone controlled-release) capsules. Advisory committee briefing materials. October 12 2008. Available at: http://www.fda.gov/ohrms/dockets/ac/08/briefing/20084395bl-02-PAIN.pdf. Accessed April 25, 2010.

93. Friedmann N, de Kater AW, Butera PG, Webster LR, Radcliffe S, Langford RM. A novel, long-acting oxycodone formulation deters abuse in humans. Presented at: 3rd International Congress World Institute of Pain; September 2004; Barcelona, Spain.

94. Gilderman L, Butera PG, Gilmore D, Moran LV, Friedmann N. Remoxy: a new opioid drug with effective analgesia and abuse-resistance. Presented at: 25th Annual Meeting of the American Pain Society; May 2006; San Antonio, TX.

95. Fleming A, Noonan P, Wheeler A. Abuse-deterrent properties and pharmacokinetics of a novel sustained release formulation of oxycodone for the treatment of moderate to severe pain. J Pain. 2008;9(Suppl 4):46.

96. Medical News Today. Pain therapeutics receives complete response letter from FDA for REMOXY(R). December 12, 2008. Available at: http://www. medicalnewstoday.com/articles/132740.php. Accessed April 25, 2010

97. Collegium Pharmaceutical, Inc. Collegium Pharmaceutical Inc. announces submission of a request for special protocol assessment to FDA for pivotal trial for tamper resistant, extended release opioid (COL-003). June 10, 2009. Available at: http://www.collegiumpharma.com/news/20090610.html. Accessed April 25, 2010. 